\title{
PENDEKATAN CONTEXTUAL TEACHING AND LEARNING (CTL) UNTUK MENINGKATKAN PEMAHAMAN MATEMATIK SISWA PADA MATERI ARITMATIKA SOSIAL
}

\author{
Musyafa', Warsali' ${ }^{2}$, Cecep Saepul Milah ${ }^{3}$, Aliyudin ${ }^{4}$, In In Supianti ${ }^{5}$, Asep Amam ${ }^{6}$ \\ 1,2,3,4,5 Universitas Pasundan, Jl. Sumatera No.41 Bandung, Indonesia \\ 6 Universitas Galuh, Jl. R. E. Martadinata No.150 Ciamis, Indonesia \\ Email: musyafa86@gmail.com
}

\begin{abstract}
The study aims to determine the enhancement of students' mathematical learning understanding through Contextual Teaching and Learning (CTL) approaches. This article is the result of class action research, conducted over two cycles. The method used in this study is a qualitative descriptive method. This research was conducted in class VII A SMP Plus Nurul Hidayah Garut. Researchers know that in general understanding of student mathematics material is still low. Based on the achievement analysis of the submission with the $65 \mathrm{KKM}$. The average student learning score before action is 35.89 out of 32 students with the highest score of 85 and the lowest value of 15 . After the action is achieved, the average results of the mathematical understanding increased from $70.95 \%$ in the I cycle to $72.86 \%$ in the II cycle. While the absorption of mathematics from $73.81 \%$ in cycle I to $88.09 \%$ in cycle II. Thus the learning model with the CTL approach can improve the student's mathematical understanding of social arithmetic material.
\end{abstract}

Keywords: Contextual teaching and learning, mathematical understanding, social arithmetic, class action research

\section{ABSTRAK}

Penelitian ini bertujuan untuk mengetahui peningkatan pemahaman belajar matematika siswa melalui pendekatan Contextual Teaching and Learning (CTL). Artikel ini merupakan hasil dari penelitian tindakan kelas, dilakukan selama dua siklus. Metode yang digunakan dalam penelitian ini adalah metode deskriptif kualitatif. Penelitian ini dilakukan di kelas VII A SMP Plus Nurul Hidayah Garut. Peneliti mengetahui bahwa secara umum pemahaman terhadap materi matematika siswa tergolong masih rendah. Berdasarkan analisis pencapaian ketuntasan dengan KKM 65. Rata-rata nilai hasil belajar peserta didik sebelum tindakan sebesar 35,89 dari 32 siswa dengan nilai tertinggi 85 dan nilai terendah 15 . Setelah dilakukan tindakan, diperoleh hasil rata-rata pemahaman matematik meningkat dari $70,95 \%$ pada siklus I menjadi $72,86 \%$ pada siklus II. Sedangkan daya serap matematika dari $73,81 \%$ pada siklus I menjadi $88,09 \%$ pada siklus II. Dengan demikian model pembelajaran dengan pendekatan CTL dapat meningkatkan pemahaman matematik siswa pada materi aritmatika sosial.

Kata kunci: Contextual teaching and learning, pemahaman matematik, aritmatika sosial, penelitian tindakan kelas

Dikirim: 25 Januari 2020; Diterima: 15 Februari 2020; Dipublikasikan: 30 Maret 2020

Cara sitasi: Musyafa., Warsali., Milah, C. S., Aliyudin, Supianti, I. I., \& Amam, A. (2020). Pendekatan contextual teaching and learning (ctl) untuk meningkatkan pemahaman matematik siswa pada materi aritmatika sosial. Teorema: Teori dan Riset Matematika, 5(1), 69-76. 


\section{PENDAHULUAN}

Matematika merupakan salah satu cabang dari ilmu pengetahuan yang banyak mendasari terhadap perkembangan ilmu pengetahuan lain, memiliki peranan yang penting dalam kehidupan manusia. Dalam kehidupan sehari-hari manusia tidak bisa lepas dari matematika. Karena matematika digunakan untuk memecahkan berbagai masalah. Matematika memiliki objek dan tujuan abstrak, bertumpu pada kesepakatan dan pola pikir yang deduktif (Hudojo, 1998).

Matematika pada hakikatnya merupakan suatu ilmu yang didasarkan atas akal (rasio) yang berhubungan benda-benda dalam pikiran yang abstrak atau matematika memiliki objek kajian yang abstrak (Prasetya \& Ahmadi, 2015). Hal ini sesuai dengan pendapat Hudojo (1998), yang menyatakan bahwa matematika merupakan ilmu yang berkenaan dengan hal-hal abstrak yang tersusun secara hierarkis dan penalaran deduktif. Jadi matematika lebih luas dari sekedar rumus-rumus dan perhitungan yang rumit, yang dianggap oleh kebanyakan peserta didik sebagai mata pelajaran yang rumit dan tidak menarik.

Matematika sebagai ilmu pengetahuan tentang benda-benda abstrak menjadi salah satu penyebab kesulitan dalam mempelajarinya. Siswa masih mengalami kesulitan dalam belajar matematika berakibat pada rendahnya pemahaman matematik siswa. Faktor yang menyebabkan rendahnya pemahaman matematis siswa, salah satunya yaitu berkaitan dengan pembelajaran di sekolah, misalnya metode mengajar matematika yang masih terpusat pada guru, sementara siswa cenderung pasif (Ruswana, 2016). Oleh karena itu, diperlukan pendekatan pembelajaran agar siswa mudah memahami materi matematika.

Salah satu pendekatan yang diharapkan dapat meningkatkan kemampuan matematis siswa adalah pendekatan kontekstual (Zakiah, 2017). Pendekatan kontekstual atau Contextual Teaching and Learning (CTL) sering bersentuhan dengan siswa, yaitu suatu pendekatan yang menghubungkan dengan kehidupan sehari-hari. The mathematical connection ability is the ability to associate between mathematical concepts with other fields in other fields of study as well as with everyday life (Selvianiresa \& Prabawanto, 2017). Dengan pendekatan CTL diharapkan dapat mempermudah siswa dalam memahami materi pelajaran matematika, sehingga dapat meningkatkan pemahaman siswa dalam belajar matematika. Pengajaran dan pembelajaran kontekstual dapat mengisi kesenjangan antara konsep matematika abstrak dan praktik kehidupan nyata (Yildiz \& Baltaci, 2016).

Pembelajaran dengan pendekatan CTL merupakan suatu sistem pengajaran yang menghubungkan muatan akademik dengan konteks dari kehidupan sehari-hari (Johnson, 2014). Hal ini sependapat dengan Glynn \& Winter (2004) "Contextual teaching and learning integrates inquiry problem and project based learning cooperative elearning and authentic assessment. Penggunaan masalah kontekstual dalam kehidupan sehari-hari dapat membantu siswa dalam memahami materi (Zakiah, Sunaryo \& Amam, 2019). Dengan pendekatan CTL diharapkan anak dapat membangun pengetahuan di dalam benaknya sendiri (Nurhadi, 2004). Sistem CTL menurut Jhonson (2014) ada delapan komponen, yaitu: (1) membuat keterkaitan-keterkaitan yang bermakna; (2) melakukan pekerjaan yang berarti; (3) melakukan pekerjaan yang diatur sendiri; (4) bekerja sama; (5) berpikir kritis dan kreatif; (6) membantu individu untuk tumbuh dan berkembang; (7) mencapai standar yang tinggi, dan (8) menggunakan penilaian yang autentik.

Berdasarkan hasil observasi yang dilakukan peneliti dan dari pangalaman mengajar guru matematika kelas VII A SMP Plus Nurul Hidayah Garut, peneliti mengetahui bahwa secara umum pemahaman terhadap materi matematika siswa tergolong masih rendah. Berdasarkan analisis pencapaian ketuntasan dengan KKM 65. Rata-rata nilai hasil belajar peserta didik sebelum tindakan sebesar 35,89 dari 32 siswa dengan nilai tertinggi 85 dan nilai terendah 15. Hal ini dapat dilihat dari nilai ulangan pada materi bentuk aljabar. Karena pada materi tersebut terlihat masih asing, yaitu dari mulai ke hal-hal yang abstrak. Materi aljabar merupakan materi yang sangat penting untuk dipelajari dan dikuasai siswa. Aljabar dapat digunakan untuk memecahkan berbagai permasalahan matematis aritmatika, soal-soal cerita, problem solving dan masalah sehari-hari. 
Melihat permasalahan di SMP Plus Nurul Hidayah Garut peneliti tertarik untuk menggunakan pendekatan Contextual Teaching and Learning (CTL) dengan tujuan agar pemahaman matematik siswa semakin meningkat. Melalui pendekatan CTL sangat memungkinkan terciptanya suasana belajar yang menyenangkan, menumbuhkan pemahaman lebih mendalam, meningkatkan hasil belajar yang lebih bermakna, meningkatkan komunikasi dan interaksi dengan guru dan menciptakan suasana pembelajaran yang kondusif.

Berdasarkan uraian yang telah dipaparkan maka dapat dirumuskan masalah sebagai berikut: "Apakah pembelajaran matematika dengan menggunakan pendekatan Contextual Teaching and Learning $(\mathrm{CTL})$ dapat meningkatkan pemahaman belajar matematik siswa di kelas VII A SMP Plus Nurul Hidayah Garut?".

\section{METODE PENELITIAN}

Jenis penelitian yang digunakan adalah Penelitian Tindakan Kelas (PTK) yang dilakukan secara kolaboratif. Kolaboratif artinya peneliti berkolaborasi atau bekerja sama dengan guru matematika yang lainnya di SMP Plus Nurul Hidayah Garut. Tindakan yang direncanakan berupa pembelajaran dengan menggunakan pendekatan Contextual Teaching and Learning (CTL) untuk meningkatkan pemahaman matematika siswa SMP Plus Nurul Hidayah Garut di kelas VII A dengan jumlah siswa 32 orang.

Penelitian ini dilaksanakan di kelas VII A SMP Plus Nurul Hidayah Garut, yang terletak di Cinta, Karangtengah, Kabupaten Garut, Jawa Barat 44184, dilaksanakan pada bulan Oktober sampai November 2019. Pembelajaran Matematika ini didesain dengan menggunakan pendekatan Contextual Teaching and Learning (CTL).

Model desain dalam penelitian ini terdiri dari komponen planning, acting, observing, dan reflecting yang dapat digambarkan seperti gambar berikut.

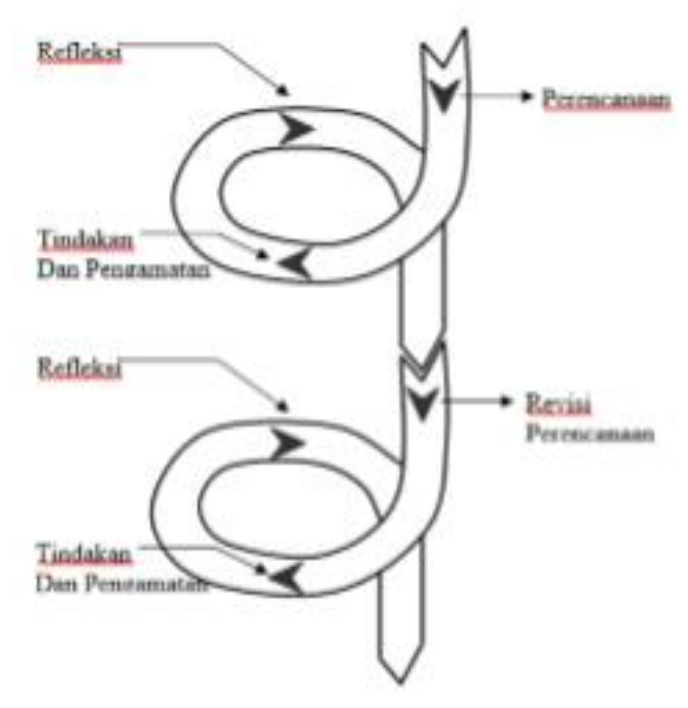

Gambar 1. Spiral penelitian tindakan kelas

Analisa data dilakukan menggunakan analisis deskriptif yang dapat diuraikan secara singkat sebagai berikut. Nilai hasil tes individu/kuis dilakukan dengan analisis ketercapaian ketuntasan dengan batas ketuntasan adalah KKM Matematika kelas VII yaitu 65. Sedangkan analisa data tentang kemampuan guru mengelola pembelajaran dilakukan dengan persentase. Persentase pengamatan kemampuan guru diperoleh dari jumlah total perolehan skor hasil pengamatan dibagi dengan skor maksimum seluruh aspek yang diamati dikalikan 100\%. Kemampuan guru mengelola pembelajaran berada dalam kategori baik jika aspek yang diamati tercapai lebih dari $76 \%$.

Sumber data dalam penelitian ini adalah hasil tes individu/kuis dan hasil pengamatan kemampuan guru dalam mengelola pembelajaran yang dilaksanakan pada setiap akhir siklus. 
Instrumen yang digunakan dalam penelitian ini adalah soal tes individu/kuis dan lembar pengamatan kemampuan guru dalam mengelola pembelajaran. Pengumpulan data dilakukan dengan cara sebagai berikut.

\section{Perencanaan (Planning) atau Persiapan Awal.}

Pada tahap ini peneliti bersama guru bidang studi dan guru kelas merencanakan kegiatan dan menetapkan waktu dan cara penyajian. Menyiapkan alat observasi untuk aktivitas siswa saat pembelajaran, menentukan alternatif tindakan yang dapat dilakukan, menyusun rencana tindakan, menyiapkan alat dan teknis analisis data.

2. Tindakan (Action)

Tindakan (action) merupakan tahap pelaksanaan dari perencanaan. Pada tahap ini peneliti melaksanakan tindakan yang telah disepakati bersama pada tahap perencanaan.

3. Pengamatan (Observation)

Pada tahap ini guru bersama peneliti mengobservasi tindakan yang dilakukan dengan teknik observasi dan catatan lapangan.

4. Refleksi (Reflection)

Refleksi (reflection) merupakan tahap akhir dari suatu daur penelitian tindakan kelas. Pada tahap ini guru dan peneliti mendiskusikan hasil tindakan dan masalah yang terjadi di kelas penelitian. Refleksi dapat ditentukan setelah adanya implementasi tindakan dan hasil observasi. Setelah melakukan refleksi biasanya muncul permasalahan atau pemikiran baru, sehingga merasa perlu melaksanakan perencanaan ulang, tindakan ulang, atau pengamatan ulang.

\section{HASIL DAN PEMBAHASAN}

Pembelajaran matematika yang biasa berlangsung pada kelas VII A adalah dengan menggunakan metode ceramah dan tanya jawab. Kegiatan pembelajaran masih didominasi oleh guru, karena setiap memulai pembelajaran guru terlebih dahulu menerangkan materi, memberikan konsep kepada siswa, setelah itu siswa mencatat. Untuk melihat apakah siswa memahami materi, guru memberi kesempatan kepada siswa untuk bertanya dan biasanya kesempatan tersebut kurang digunakan, hal ini terlihat dari jarangnya siswa yang mengajukan pertanyaan. Pada saat guru menjelaskan biasanya tidak semua siswa memperhatikan, namun ada beberapa orang siswa yang mengobrol dengan temannya, melamun, bahkan ada pula yang mengantuk.

Komunikasi yang terjadi dalam pembelajaran adalah komunikasi satu arah, yaitu guru ke siswa. Biasanya siswa ragu-ragu untuk mengemukakan pendapat, atau untuk bertanya. Sebagian siswa yang ingin memahami materi yang sedang dipelajari memilih untuk bertanya terhadap teman sebangkunya, atau lebih baik diam. Jika guru memberikan pertanyaan, siswa menjawab dengan beramai-ramai dan jika guru menunjuk pada salah seorang diantaranya, biasanya siswa tersebut tidak mau mengemukakan pendapatnya karena malu atau takut salah. Setelah selesai menyampaikan materi, guru memberikan latihan soal untuk dikerjakan oleh siswa sampai jam pelajaran habis. Dan sebelum menutup pelajaran guru biasanya memberikan PR.

Berdasarkan hasil observasi terhadap aktivitas siswa dalam pembelajaran pratindakan menunjukkan bahwa aktivitas diskusi, tampil di depan kelas untuk mempresentasikan pendapat, mengajukan pertanyaan atau pendapat, dan untuk bisa menarik kesimpulan di akhir pembelajaran masih kurang.

Pada dasarnya, guru belum mengenal pendekatan Contextual Teaching and Learning (CTL), dan guru merasa tertarik untuk mencoba menggunakan pendekatan ini dalam proses belajar mengajarnya di kelas. Guru berharap dengan adanya pendekatan CTL ini dapat membuat siswa terbiasa belajar mandiri dan aktif dalam pembelajaran, siswa akan berani mengemukakan 
pendapatnya, siswa terbiasa berpikir kritis yang akan melahirkan penalaran yang baik, siswa mempunyai motivasi belajar yang tinggi karena mereka menyadari bahwasanya matematika sangat berarti bagi kehidupan. Dan pada akhirnya diharapkan dapat meningkatkan prestasi belajar matematika siswa dan prestasi sekolah mereka.

Berdasarkan observasi awal pada pembelajaran biasa, peneliti dan observer mengidentifikasi permasalahan-permasalahan yang ditemukan untuk dijadikan refleksi dalam merencanakan tindakan pembelajaran selanjutnya yang dapat dilihat pada tabel berikut ini.

Tabel 1.

Refleksi kegiatan pratindakan

\begin{tabular}{|c|c|c|}
\hline Kendala/Kesulitan guru & Catatan lapangan & Saran perbaikan \\
\hline $\begin{array}{l}\text { - Guru belum mengenal } \\
\text { pendekatan Contextual Teaching } \\
\text { and Learning (CTL). } \\
\text { - Merasa sulit untuk } \\
\text { mengembangkan kemampuan } \\
\text { dan keaktifan siswa dalam } \\
\text { pembelajaran. }\end{array}$ & $\begin{array}{l}\text { - Kegiatan pembelajaran masih } \\
\text { didominasi oleh guru. } \\
\text { - Guru hanya menggunakan metode } \\
\text { ekspositori. } \\
\\
\text { - Siswa kurang aktif dalam } \\
\text { pembelajaran } \\
\text { - Sangat sedikit siswa yang berani } \\
\text { mengajukan pertanyaan atau inisiatif } \\
\text { sendiri. } \\
\text { - Guru tidak mengecek pengetahuan } \\
\text { awal siswa, guru langsung } \\
\text { memberikan penjelasan dengan } \\
\text { menggunakan metode ekspositori. }\end{array}$ & $\begin{array}{l}\text { Mencoba untuk menerapkan } \\
\text { pendekatan Contextual } \\
\text { Teaching and Learning (CTL) } \\
\text { pada pokok bahasan } \\
\text { aritmatika sosial pada } \\
\text { khususnya dan pada setiap } \\
\text { pokok bahasan matematika } \\
\text { pada umumnya. }\end{array}$ \\
\hline
\end{tabular}

Untuk mengetahui perkembangan keberhasilan belajar siswa, peneliti memberikan penilaian terhadap hasil pengerjaan LKS untuk setiap pertemuan dan hasilnya dirangkum dalam tabel berikut.

Tabel 2.

Tingkat pemahaman dan daya serap klasikal untuk setiap LKS

\begin{tabular}{ccccc}
\hline \multirow{2}{*}{ Tingkat pemahaman } & \multicolumn{5}{c}{ Lembar Kerja Siswa (LKS) } \\
& $\mathbf{1}$ & $\mathbf{2}$ & $\mathbf{3}$ & $\mathbf{4}$ \\
\hline Tingkat pemahaman tertinggi & 100 & 100 & 100 & 100 \\
Tingkat pemahaman terendah & 20 & 50 & 45 & 70 \\
Tingkat pemahaman rata-rata & 60 & 84,5 & 75,52 & 89 \\
Daya serap klasikal & 50 & 71,42 & 80,95 & 100 \\
\hline
\end{tabular}

Berdasarkan Tabel 2 tampak bahwa pemahaman tertinggi untuk setiap LKS adalah 100. Ini menunjukkan bahwa dalam setiap LKS terdapat siswa yang sudah paham $100 \%$ untuk setiap materi yang disajikan. Jika dilihat dari tingkat pemahaman ada peningkatan dari setiap LKS. Pemahaman terendah pada LKS 3 relatif menurun jika dibanding LKS 1 dan 2. Hal ini disebabkan karena pada LKS 3 materi yang disajikan lebih sulit dibanding LKS 1.

Ketuntasan belajar siswa yang diukur berdasarkan daya serap klasikal untuk LKS 1 sebesar $50 \%$, LKS 2 sebesar $71,42 \%$, LKS 3 sebesar $80,95 \%$, LKS 4 sebesar $100 \%$. Dilihat dari persentasenya sebagian besar siswa telah mencapai ketuntasan belajar. 
Jumlah LKS pada siklus I terdiri dari 2 LKS yaitu LKS 1 dan LKS 2, sedangkan jumlah LKS pada siklus II terdiri dari 2 LKS yaitu LKS 3 sampai dengan LKS 4. Rata-rata daya serap klasikal LKS untuk siklus I adalah 60,71\% sedangkan daya serap klasikal LKS untuk siklus II adalah 90,48\%. Jadi jika dilihat secara keseluruhan pemahaman matematik siswa meningkat untuk setiap LKS yaitu pada siklus I dan siklus II.

Untuk mengetahui perkembangan keberhasilan belajar siswa, peneliti juga memberikan penilaian terhadap tes hasil belajar siswa untuk setiap kali tes dan hasilnya dirangkum dalam Tabel 3.

Tabel 3.

Tingkat pemahaman tes hasil belajar

\begin{tabular}{lcc}
\hline \multirow{2}{*}{ Tingkat pemahaman } & \multicolumn{2}{c}{ Persentase setiap tes } \\
& Tes 1 & Tes 2 \\
\hline Tingkat pemahaman tertinggi & 95 & 95 \\
Tingkat pemahaman terendah & 45 & 45 \\
Tingkat pemahaman rata-rata & 70,95 & 72,86 \\
Daya serap klasikal & 73,81 & 88,09 \\
\hline
\end{tabular}

Berdasarkan Tabel 3 dapat terlihat bahwa tingkat pemahaman tertinggi dan tingkat pemahaman terendah pada kedua tes hasil belajar adalah sama, tetapi tingkat pemahaman rata-rata dan daya serap klasikal meningkat. Pemahaman rata-rata meningkat dari 70,95\% menjadi $72,86 \%$ sedangkan daya serap matematika dari $73,81 \%$ menjadi $88,09 \%$.

Dari data tersebut dapat diperoleh informasi bahwa pemahaman matematik siswa meningkat setelah pembelajaran dengan menggunakan pendekatan CTL. Berdasarkan data yang telah disajikan, maka dapat disimpulkan bahwa pembelajaran matematika dengan contextual teaching and learning dapat meningkatkan pemahaman matematik siswa. Hal ini sependapat dengan penelitian yang sudah dilakukan oleh Glynn \& Winter (2004) yang menunjukkan bahwa implementasi strategi CTL dapat meningkatkan interaksi kolaboratif dengan siswa, tingkat aktivitas yang tinggi dalam pelajaran, koneksi ke konteks dunia nyata, dan integrasi konten sains dengan konten lain dan bidang keterampilan. Lebih lanjut, strategi CTL paling baik diterapkan ketika guru menggunakannya bersamaan dengan teknik manajemen kelas yang baik (Glynn \& Winter, 2004). Hal yang sama juga diungkapkan oleh Selvianiresa \& Prabawanto (2017), dalam penelitiannya bahwa pendekatan Contextual Teaching and Learning (CTL) dapat berhasil, ketika belajar menggunakan interaksi kolaboratif dengan siswa, tingkat aktivitas yang tinggi dalam pelajaran, koneksi ke konteks dunia nyata, dan integrasi konten sains dengan konten lain dan bidang keterampilan (Selvianiresa \& Prabawanto, 2017). Selain itu, Ekowati et.al (2015), dalam penelitiannya dengan pendekatan CTL diperoleh hasil: (1) motivasi siswa terlihat meningkat; (2) peningkatan aktivitas lebih kompak dalam menyelesaikan masalah atau kasus; dan (3) meningkatnya penguasaan konsep matematis siswa.

\section{KESIMPULAN}

Berdasarkan hasil penelitian dan analisis data, maka penulis dapat menarik kesimpulan sebagai berikut: (1) model pembelajaran dengan menggunakan pendekatan Contextual Teaching and Learning (CTL) pada materi aritmatika sosial dapat meningkatkan pemahaman matematik siswa. Hal ini dapat dilihat dari kenaikan rata-rata hasil tes siklus I dan siklus II; dan (2) pembelajaran dengan 
pendekatan Contextual Teaching and Learning (CTL) pada materi aritmatika sosial sudah terlaksana dengan baik, meskipun dalam pelaksanaannya masih kekurangan waktu.

\section{REKOMENDASI}

Dengan memperhatikan hasil penelitian dan kesimpulan yang telah dikemukakan, peneliti menyarankan agar penelitian ini bisa dijadikan model pembelajaran yang efektif dan dapat meningkatkan aktivitas serta pemahaman siswa terhadap materi matematika. Sehingga akan meningkatkan kualitas pendidikan matematika siswa.

\section{UCAPAN TERIMA KASIH}

Ucapan terima kasih kami sampaikan kepada: (1) Pascasarjana UNPAS yang telah membantu penelitian ini; (2) guru dan siswa yang terlibat dan berpartisipasi dalam penelitian ini; (3) Kepala SMP Plus Nurul Hidayah Garut yang telah memberikan izin untuk melakukan penelitian: dan (4) teman-teman seperjuangan di Pascasarjana UNPAS yang telah membantu dan memberi arahan dan masukan sehingga penelitian ini dapat terlaksana.

\section{DAFTAR PUSTAKA}

Ekowati, Ch, K., Muhammad, D., Upa, H. M. D., \& Tahmir, S. (2015). The application of contextual approach in learning mathematics to improve students motivation at smpn 1 kupang. International Education Studies, 8(8), 81-86.

Glynn, S. M., \& Winter, L. K. (2004). Contextual teaching and learning of science in elementary schools. Journal of Elementary Science Education.

Hudojo, H. (1998). Mengajar belajar matematika. Jakarta: Depdikbud Dirjen Dikti Proyek Pengembangan Lembaga Pendidikan.

Jhonson, E. B. (2014). Contextual teaching and learning. Bandung: Mizan.

Nurhadi. (2004). Pembelajaran kontekstual dan penerapannya dalam kbk. Malang: UM Press.

Ruswana, A. M. (2016). Penerapan pembelajaran peer instruction with structured inquiry (pisi) untuk meningkatkan kemampuan pemahaman matematis siswa. Teorema: Teori dan Riset Matematika, 1(1), 55-65.

Selvianiresa, D., \& Prabawanto, S. (2017). Contextual teaching and learning approach of mathematics in primary schools. Journal of Physics: Conference Series, 895, 012171, 1-7.

Prasetya, J. T., \& Ahmadi, A. (2015). Strategi belajar mengajar. Bandung: CV.

Yildiz, A., \& Baltaci, S. (2016). Reflections from the analytic geometry courses based on contextual teaching and learning through geogebra software. The Online Journal of New Horizons in Education, 6(4), 155-166.

Zakiah, N. E. (2017). Pembelajaran dengan pendekatan kontekstual berbasis gaya kognitif untuk meningkatkan kemampuan metakognitif siswa. Pedagogy 2(2), 11-29. 
•76 Teorema: Teori dan Riset Matematika, 5(1), 69-76, Maret 2020

Zakiah,N. E., Sunaryo, Y., \& Amam, A. (2019). Implementasi pendekatan kontekstual pada model pembelajaran berbasis masalah berdasarkan langkah-langkah polya. Teorema: Teori dan Riset Matematika,4(2),111-120. 